\title{
Outcomes after surgical pulmonary embolectomy for acute submassive and massive pulmonary embolism: A single-center experience
}

\author{
Chetan Pasrija, MD, ${ }^{\text {a }}$ Anthony Kronfli, MD, ${ }^{a}$ Michael Rouse, BS, ${ }^{a}$ Maxwell Raithel, BS, ${ }^{a}$ \\ Gregory J. Bittle, MD, ${ }^{\text {a }}$ Sheelagh Pousatis, MD, ${ }^{\mathrm{a}}$ Mehrdad Ghoreishi, MD, ${ }^{\mathrm{a}}$ James S. Gammie, MD, ${ }^{\mathrm{a}}$ \\ Bartley P. Griffith, MD, ${ }^{a}$ Pablo G. Sanchez, MD, PhD, ${ }^{b}$ and Zachary N. Kon, MD ${ }^{a}$
}

\begin{abstract}
Objectives: Ideal treatment strategies for submassive and massive pulmonary embolism remain unclear. Recent reports of surgical pulmonary embolectomy have demonstrated improved outcomes, but surgical technique and postoperative outcomes continue to be refined. The aim of this study is to describe in-hospital survival and right ventricular function after surgical pulmonary embolectomy for submassive and massive pulmonary embolism with excessive predicted mortality $(\geq 5 \%)$.
\end{abstract}

Methods: All patients undergoing surgical pulmonary embolectomy (2011-2015) were retrospectively reviewed. Patients with pulmonary embolism were stratified as submassive, massive without arrest, and massive with arrest. Submassive was defined as normotensive with right ventricular dysfunction. Massive was defined as prolonged hypotension due to the pulmonary embolism. Preoperative demographics, intraoperative variables, and postoperative outcomes were compared.

Results: A total of 55 patients were identified: 28 as submassive, 18 as massive without arrest, and 9 as massive with arrest. All patients had a right ventricle/ left ventricle ratio greater than 1.0. Right ventricular dysfunction decreased from moderate preoperatively to none before discharge $(P<.001)$. In-hospital and 1-year survival were $93 \%$ and $91 \%$, respectively, with $100 \%$ survival in the submassive group. No patients developed renal failure requiring hemodialysis at discharge or had a postoperative stroke.

Conclusions: In this single institution experience, surgical pulmonary embolectomy is a safe and effective therapy to treat patients with a submassive or massive pulmonary embolism. Although survival in this study is higher than previously reported for patients treated with medical therapy alone, a prospective trial comparing surgical therapy with medical therapy is necessary to further elucidate the role of surgical pulmonary embolectomy in the treatment of pulmonary embolism. (J Thorac Cardiovasc Surg 2018;155:1095-106)

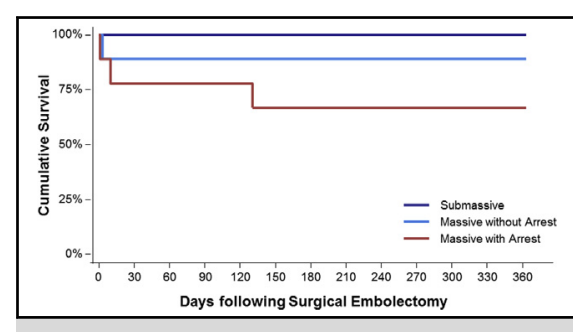

Kaplan-Meier survival curve for patients undergoing surgical pulmonary embolectomy.

\section{Central Message}

Surgical pulmonary embolectomy is a safe and effective treatment for submassive and massive PE.

\section{Perspective}

This series demonstrates that surgical pulmonary embolectomy is a safe and effective therapy for patients with a submassive or massive PE. Although survival in this study is higher than previously reported with medical therapy, a prospective trial comparing surgical with medical therapy is needed to elucidate the role of surgical pulmonary embolectomy in the treatment of PE.

See Editorial Commentary page 1107.

See Editorial page 1082
From the a Division of Cardiac Surgery, University of Maryland School of Medicine, Baltimore, Md; and ${ }^{\mathrm{b}}$ Division of Thoracic Surgery, University of Washington School of Medicine, Seattle, Wash.

Read at the 42nd Annual Meeting of The Western Thoracic Surgical Association, Waikoloa, Hawaii, June 22-25, 2016.

Received for publication June 29, 2016; revisions received Sept 18, 2017; accepted for publication Oct 8, 2017

Address for reprints: Chetan Pasrija, MD, Division of Cardiac Surgery, University of Maryland School of Medicine, 110 S Paca St, 7th Floor, Baltimore, MD 21201

(E-mail: cpasrija@smail.umaryland.edu).

$0022-5223 / \$ 36.00$

Copyright (C) 2017 by The American Association for Thoracic Surgery

https://doi.org/10.1016/j.jtcvs.2017.10.139
Acute pulmonary embolism (PE) is estimated to cause 100,000 to 180,000 deaths per year. ${ }^{1}$ It remains the single most preventable cause of death among hospitalized

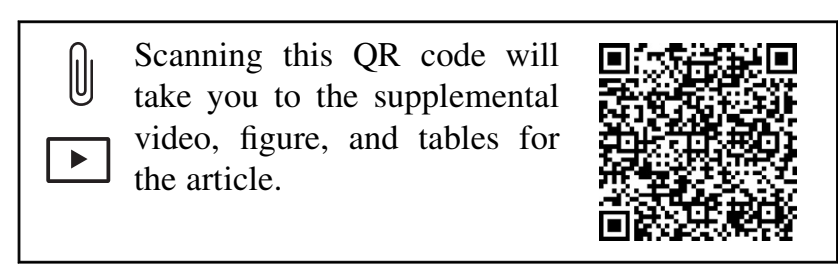




\section{Abbreviations and Acronyms \\ AHA $=$ American Heart Association \\ $\mathrm{LV}=$ left ventricular \\ $\mathrm{PE} \quad=$ pulmonary embolism \\ PESI = Pulmonary Embolism Severity Index \\ RIETE $=$ Computerized Registry of Patients with \\ Venous Thromboembolism \\ $\mathrm{RV} \quad=$ right ventricular \\ STS = Society of Thoracic Surgeons}

patients. ${ }^{2,3}$ In addressing this potentially fatal condition, a number of studies over the past 20 years have demonstrated a correlation between right ventricular (RV) failure and increasing mortality. ${ }^{4-6}$ However, the appropriate treatment for patients with submassive PE or massive PE remains unclear.

Presently, the mainstay of treatment for PE is systemic anticoagulation. However, there remains significant controversy among additional therapies, including systemic thrombolysis, catheter-directed pulmonary embolectomy or localized thrombolysis, and surgical pulmonary embolectomy. Current guidelines support the use of thrombolytics in patients with a massive PE or submassive PE at high risk for adverse events. ${ }^{7}$ However, large retrospective series and even large randomized controlled trials of systemic thrombolysis compared with heparin therapy alone have failed to demonstrate a mortality benefit. ${ }^{4,8}$ Furthermore, thrombolytic therapy is associated with a $2 \%$ to $7 \%$ risk of intracranial hemorrhage..$^{5,8-12}$

According to the American Heart Association (AHA), recommendation for surgical pulmonary embolectomy is limited to patients with a massive PE who have a contraindication to thrombolysis. ${ }^{7}$ Much of the data leading to these recommendations are based on historical surgical series in which patients were taken to the operating room in extremis. As such, mortality rates for embolectomy have been reported between $20 \%$ and $50 \% .{ }^{13-16}$ Over the past decade, there have been multiple reports demonstrating that early, aggressive surgical intervention can lead to excellent survival for submassive and massive PE. ${ }^{17-21}$ Still, perioperative factors, surgical timing, and operative technique continue to be refined as experience with this operation grows. Moreover, the severity of RV dysfunction before the operation and recovery postembolectomy have yet to be well defined. In this single institution cohort, we aimed to analyze in-hospital survival and RV function after surgical pulmonary embolectomy for submassive and massive PE.

\section{PATIENTS AND METHODS \\ Patients}

With Institutional Review Board approval (HP-00066712), a retrospective review of the institutional cardiac surgery database was performed for all patients who underwent surgical pulmonary embolectomy (procedure code 33910 and 33916) for acute PE from January 1, 2011, to October 31, 2015, at the University of Maryland Medical Center. A manual review of patient charts was performed to confirm the operative procedure and obtain preoperative, perioperative, and postoperative variables and outcomes. Markers of RV dysfunction (troponin and N-terminal prohormone of brain natriuretic peptide) were recorded as the highest values before surgical intervention. Preoperative vital signs (heart rate, respiratory rate, blood pressure, oxygen saturation) were recorded at presentation. PE was identified by computed tomography angiography in all cases. RV dysfunction was recorded on the basis of preoperative and postoperative (before discharge) transthoracic echocardiograms. RV dysfunction (none to severe) was delineated by an independent cardiologist, who both quantitatively and qualitatively assessed RV function to obtain an overall assessment of dysfunction.

Patients were stratified into 3 categories: submassive PE, massive PE without arrest, and massive PE with arrest. Submassive PE was defined, per the AHA, as patients with a systolic blood pressure greater than $90 \mathrm{~mm} \mathrm{Hg}$ but with echocardiographic signs of RV dysfunction or dilation, computed tomography signs of RV dilation, or laboratory findings suggesting myocardial necrosis. ${ }^{7}$ Massive PE without arrest was defined as patients with a systolic blood pressure less than $90 \mathrm{~mm} \mathrm{Hg}$ for at least 15 minutes or requiring inotropic support, not due to a cause other than $\mathrm{PE}$, or persistent profound bradycardia (heart rate $<40$ beats/min with signs or symptoms of shock), ${ }^{7}$ without the presence of a cardiac arrest. Massive PE with arrest was defined similarly, but included only patients with a loss of pulse requiring cardiopulmonary resuscitation.

\section{Indications for Operation}

Among patients who were referred for surgical pulmonary embolectomy with a diagnosis of submassive or massive PE, surgical intervention was offered if their predicted risk of 30-day mortality was greater than or equal to $5 \%$. Predicted risk of mortality associated with PE was estimated for all patients at the time of referral for surgical treatment. There are 2 internally and externally validated risk models for mortality associated with PE: the Bova score, which is valid only for high-risk normotensive (submassive PE) patients, and the Pulmonary Embolism Severity Index (PESI) score, which applies to all patients with PE. Although the Bova score accounts for only physiologic measures, the PESI score includes patient vital signs along with patient variables such as age, sex, and comorbidities (Figure 1). Predicted mortality was based on the Bova score, PESI score, and cardiac biomarkers. ${ }^{22-24}$ Patients with comorbid conditions were only denied surgical intervention when estimated survival was less than 1 year, independent of the PE.

Patients with a predicted 30-day mortality rate less than 5\% were treated with medical therapy and observed. If signs or symptoms of progressive RV or cardiovascular failure manifested, patients were reevaluated for surgical pulmonary embolectomy. All patients in this series had a predicted mortality rate greater than or equal to $5 \%$ on initial presentation.

Timing of surgery, even in situations in which previous thrombolytic therapy was given or the patient was placed on venoarterial extracorporeal membrane oxygenation, was left to the surgeon's discretion (median time from admission to operating room was 4 hours). Patients were not screened on the basis of the location of thrombus. Patients with central or distal thrombus were evaluated equally for surgical intervention.

\section{Operative Technique and Postoperative Management}

Before induction of anesthesia, all patients were prepped and prepared for incision, in case the patient became unstable on induction. All patients were placed on cardiopulmonary bypass with mild hypothermia via median sternotomy. Central aortic and bicaval venous cannulation was used. Separate incisions were made in the right and left main pulmonary artery. By 


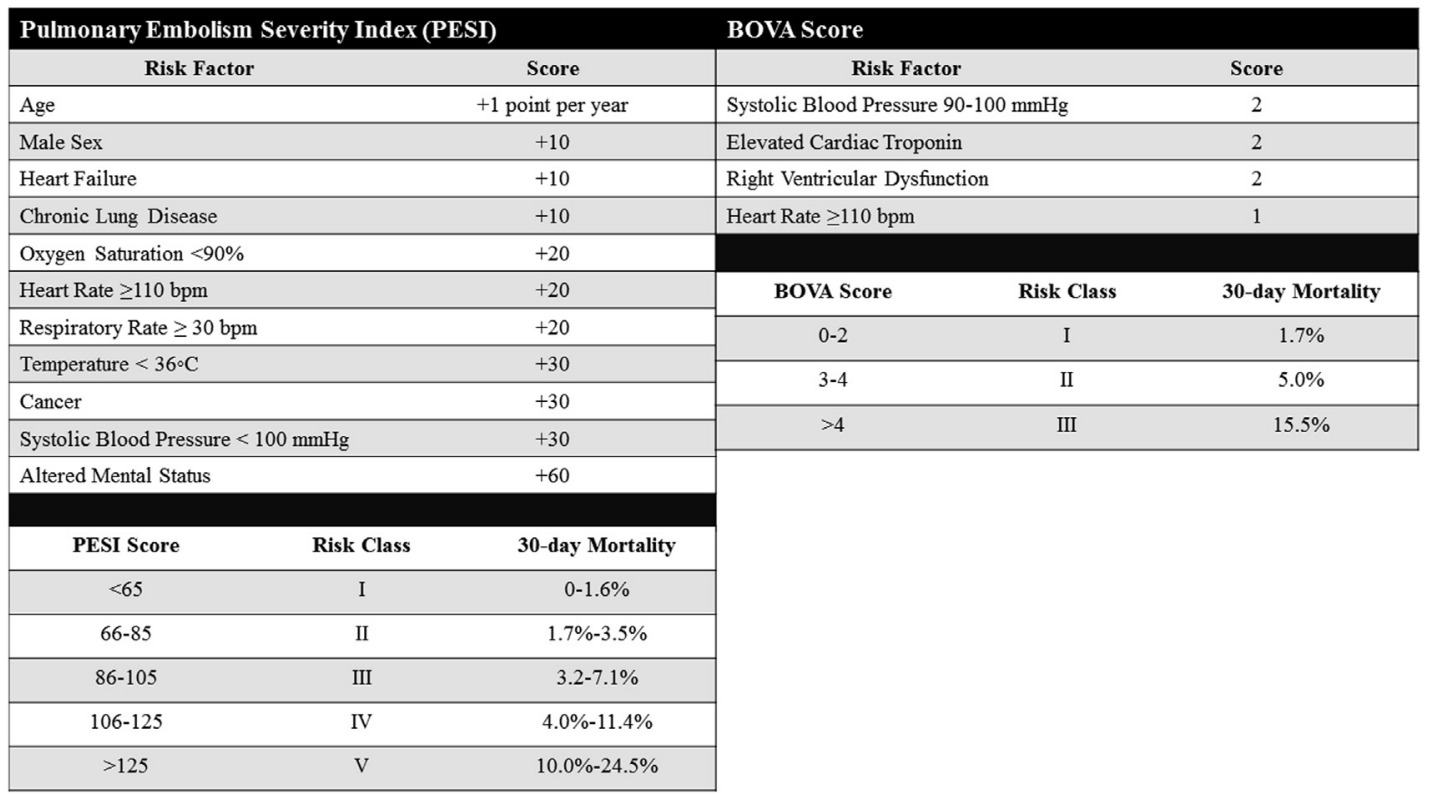

FIGURE 1. Scoring and predicted mortality based on PESI score and Bova score.

using a combination of forceps and suction extraction, the thrombus was gently and carefully removed, in its entirety, up to the subsegmental level. Intermittent, 15- to 30-second circulatory arrest periods were initiated as necessary. The operation was routinely performed on a beating heart without placement of an aortic crossclamp.

In cases in which the patient was placed on venoarterial extracorporeal membrane oxygenation before the operation, the existing venous cannula in the femoral vein was used as the inferior vena cava cannula and the existing arterial cannula in the femoral artery was used as the aortic cannula. A separately placed superior vena cava cannula was then added in a "Y" fashion to the venous line.

Postoperatively, anticoagulation was restarted after the total chest tube output was less than $30 \mathrm{~mL} / \mathrm{h}$ for 3 consecutive hours, initially with a partial thromboplastin time of 45 to 55 seconds for 24 hours and then to a partial thromboplastin time of 60 to 80 seconds. All patients received an inferior vena cava filter, and transthoracic echocardiogram was performed before discharge.

\section{Clinical Outcomes}

The primary outcomes of this study were in-hospital survival and postoperative RV dysfunction. Secondary outcomes included 30-day survival, 1 -year survival, postoperative stroke, acute kidney injury as defined by the Society of Thoracic Surgeons (STS) (increase of serum creatinine to $\geq 4.0 \mathrm{mg} / \mathrm{dL}$ or $3 \times$ the most recent preoperative creatinine level (acute increase must be at least $0.5 \mathrm{mg} / \mathrm{dL}$ ), a new requirement for dialysis postoperatively), new hemodialysis at discharge, pneumonia, prolonged intubation ( $>24$ hours postoperatively), tracheostomy, deep sternal wound infection, and sepsis.

\section{Statistical Analysis}

Continuous variables are presented as median with interquartile range and were compared using the Kruskal-Wallis test. Post hoc, pairwise comparisons were performed using Dunn's test with the Bonferroni correction for multiple comparisons. Categoric variables are presented as $\mathrm{N}(\%)$ and were compared using the Fisher exact test, with post hoc analysis using the Fisher exact test with the Bonferroni correction. Pairwise significance is indicated by paired asterisks $(*)$ or daggers $(\dagger)$ within a row. For analysis and presentation purposes, the descriptive terms used by the echocardiographer were converted to numeric values according to the following rubric: none -0 , mild -1 , moderate -2 , and severe -3 . In addition to reporting the appropriate medians, paired preoperative and postoperative measurements of RV dysfunction were compared using the test of marginal homogeneity. Survival was calculated as time from surgery to death and was censored for loss to follow-up using the Kaplan-Meier method. Censoring was performed per standard practice if the last confirmed follow-up occurred before the end of the study or if patients were still alive at the end of the study. The number of patients at risk at each time point was recorded The differences in survival curves were assessed using the log-rank test.

\section{RESULTS}

\section{Patient Demographics and Risk Factors for Pulmonary Embolism}

A total of 55 patients underwent surgical pulmonary embolectomy during the study time period: $28(51 \%)$ were submassive, $18(33 \%)$ were massive without arrest, and 9 $(16 \%)$ were massive with arrest. Outside of an increased incidence of recent surgery in the massive without arrest cohort compared with the submassive cohort, there were no significant differences in risk factors or comorbidities among the 3 groups (Tables 1, E1, and E2).

\section{Predicted Mortality and Preoperative Variables}

Patients in all groups had significant RV dysfunction, evaluated by an elevated troponin, elevated $\mathrm{N}$-terminal prohormone of brain natriuretic peptide, and transthoracic echocardiographic evidence of RV dysfunction (Table 2). Contraindications to thrombolysis were identified in $16 \%$ of patients (9/55). The median PESI (all 3 groups) and median Bova (submassive only) scores placed all patients in the highest mortality risk class. On the basis of PESI score, 
TABLE 1. Patient demographics and risk factors for pulmonary embolism

\begin{tabular}{|c|c|c|c|c|c|}
\hline & Overall $(n=55)$ & Submassive $(\mathrm{n}=\mathbf{2 8})$ & $\begin{array}{l}\text { Massive without arrest } \\
\qquad(\mathrm{n}=18)\end{array}$ & $\begin{array}{l}\text { Massive with arrest } \\
\qquad(\mathrm{n}=9)\end{array}$ & $P$ value \\
\hline Age (y) & $53(44-64)$ & $50(41-63)$ & $55(46-63)$ & $57(43-67)$ & NS \\
\hline Male & $33(60 \%)$ & $17(61 \%)$ & $10(55 \%)$ & $6(67 \%)$ & NS \\
\hline Race & & & & & NS \\
\hline African-American & $21(38 \%)$ & $12(43 \%)$ & $7(39 \%)$ & $2(22 \%)$ & \\
\hline White & $30(55 \%)$ & $14(50 \%)$ & $9(50 \%)$ & $7(78 \%)$ & \\
\hline Other & $4(7 \%)$ & $2(7 \%)$ & $2(11 \%)$ & $0(0 \%)$ & \\
\hline \multicolumn{6}{|l|}{ Medical history } \\
\hline Chronic lung disease & $5(9 \%)$ & $2(7 \%)$ & $2(11 \%)$ & $1(11 \%)$ & NS \\
\hline $\mathrm{CHF}$ & $1(2 \%)$ & $1(4 \%)$ & $0(0 \%)$ & $0(0 \%)$ & NS \\
\hline DVT & $44(80 \%)$ & $22(79 \%)$ & $14(78 \%)$ & $8(89 \%)$ & NS \\
\hline Malignancy & $8(15 \%)$ & $3(11 \%)$ & $3(17 \%)$ & $2(22 \%)$ & NS \\
\hline Obesity & $34(62 \%)$ & $15(54 \%)$ & $13(72 \%)$ & $6(67 \%)$ & NS \\
\hline Prior PE & $3(6 \%)$ & $0(0 \%)$ & $3(17 \%)$ & $0(0 \%)$ & NS \\
\hline Recent surgery $(<1 \mathrm{mo})$ & $21(38 \%)$ & $6(21 \%)^{*}$ & $11(61 \%)^{*}$ & $4(44 \%)$ & .024 \\
\hline \multicolumn{6}{|l|}{ Surgery type } \\
\hline General surgery & $3(14 \%)$ & $1(17 \%)$ & $2(18 \%)$ & $0(0 \%)$ & NS \\
\hline Neurosurgery & $3(14 \%)$ & $0(0 \%)$ & $2(18 \%)$ & $1(25 \%)$ & NS \\
\hline Orthopedic & $10(48 \%)$ & $3(50 \%)$ & $4(36 \%)$ & $3(75 \%)$ & NS \\
\hline Other & $5(24 \%)$ & $2(33 \%)$ & $3(27 \%)$ & $0(0 \%)$ & NS \\
\hline
\end{tabular}

$N S$, Not significant; $C H F$, congestive heart failure; $D V T$, deep vein thrombosis; $P E$, pulmonary embolism. *Denotes significance between 2 starred groups.

median predicted 30-day mortality range for all 3 cohorts was $10 \%$ to $25.5 \%$. Specifically in the submassive group, the Bova score predicted a median 30-day mortality rate of $15.5 \%$ (Table 3$)$.

\section{Perioperative Variables and Outcomes}

Overall, in-hospital survival was $93 \%$ with $100 \%$ survival in patients with a submassive PE (Table 4). KaplanMeier survival curves for each cohort are presented in
Figure 2. In the massive PE without arrest cohort, there were 2 deaths: Both patients had significant preoperative strokes, and care was withdrawn because of poor neurologic prognosis. In the massive PE with arrest cohort, there were 2 in-hospital deaths: 1 patient with a significant preoperative stroke leading to withdrawal of care and 1 patient with preoperative multisystem organ failure who developed diffuse coagulopathy postoperatively with progression of organ failure (Figure E1). In-hospital survival was equivalent to

TABLE 2. Preoperative clinical variables

\begin{tabular}{|c|c|c|c|c|c|}
\hline & Overall $(\mathbf{n}=\mathbf{5 5})$ & Submassive $(n=28)$ & $\begin{array}{l}\text { Massive without arrest } \\
\qquad(\mathrm{n}=18)\end{array}$ & $\begin{array}{l}\text { Massive with arrest } \\
\qquad(\mathbf{n}=9)\end{array}$ & $P$ value \\
\hline Troponin (ng/mL) & $0.45(0.20-1.01)$ & $0.39(0.19-0.98)$ & $0.31(0.11-1.01)$ & $0.59(0.44-0.93)$ & NS \\
\hline NT-proBNP (pg/mL) & $2990(489-4185)$ & $2590(489-4835)$ & $2995(905-3503)$ & - & NS \\
\hline $\begin{array}{l}\text { RV dysfunction } \\
\text { None } \\
\text { Mild } \\
\text { Moderate } \\
\text { Severe }\end{array}$ & $\begin{array}{c}2(4 \%) \\
5(9 \%) \\
20(36 \%) \\
17(31 \%)\end{array}$ & $\begin{array}{c}1(4 \%) \\
3(11 \%) \\
14(50 \%) \\
7(25 \%)\end{array}$ & $\begin{array}{l}1(6 \%) \\
1(6 \%) \\
5(28 \%) \\
8(45 \%)\end{array}$ & $\begin{array}{l}0(0 \%) \\
1(11 \%) \\
1(11 \%) \\
2(22 \%)\end{array}$ & NS \\
\hline Heart rate (beats/min) & $120(104-132)$ & $121(110-130)$ & $121(100-143)$ & $111(92-128)$ & NS \\
\hline $\mathrm{SBP}(\mathrm{mm} \mathrm{Hg})$ & $93(80-114)$ & $108(98-128)$ & $79(67-89)$ & $80(66-90)$ & NS \\
\hline Respiratory rate (beats/min) & $29(26-34)$ & $29(25-34)$ & $28(26-33)$ & $32(28-35)$ & NS \\
\hline $\mathrm{FIO}_{2}(\%)$ & $50(30-100)$ & $37(27-53)^{*}, \dagger$ & $100(40-100)^{*}$ & $100(100-100) \dagger$ & .001 \\
\hline VA-ECMO & $6(11 \%)$ & $0(0 \%)^{*}$ & $4(22 \%)$ & $2(22 \%)^{*}$ & .003 \\
\hline
\end{tabular}

$N S$, Not significant; NT-proBNP, N-terminal prohormone of brain natriuretic peptide; $R V$, right ventricular; $S B P$, systolic blood pressure; $F_{10}$, inspired oxygen fraction; $V A-E C M O$, venoarterial extracorporeal membrane oxygenation. *Denotes significance between 2 starred groups. † $\dagger$ Denotes significance between 2 daggered groups. 
TABLE 3. Surgical groups and predicted risk scores

\begin{tabular}{lcccc}
\hline & $\begin{array}{c}\text { Submassive } \\
(\mathbf{n = 2 8})\end{array}$ & $\begin{array}{c}\text { Massive } \\
\text { without arrest } \\
(\mathbf{n = 1 8})\end{array}$ & $\begin{array}{c}\text { Massive with } \\
\text { arrest }(\mathbf{n = 9 )}\end{array}$ & $\begin{array}{c}\boldsymbol{P} \\
\text { value }\end{array}$ \\
\hline Bova score & $5(4-7)$ & - & - & - \\
Bova class & & & & - \\
I & $0(0 \%)$ & - & - & \\
II & $7(25 \%)$ & - & - & \\
III & $21(75 \%)$ & - & - & \\
PESI score & $135(111-159)^{*}, \dagger$ & $181(130-201) *$ & $186(143-207) \dagger$ & .003 \\
PESI class & & & & NS \\
I & $1(4 \%)$ & $0(0 \%)$ & $0(0 \%)$ & \\
II & $0(0 \%)$ & $0(0 \%)$ & $0(0 \%)$ & \\
III & $4(14 \%)$ & $0(0 \%)$ & $0(0 \%)$ & \\
IV & $6(21 \%)$ & $2(11 \%)$ & $0(0 \%)$ & \\
V & $17(61 \%)$ & $16(89 \%)$ & $9(100 \%)$ & \\
\hline
\end{tabular}

PESI, Pulmonary Embolism Score Index; NS, not significant. *Denotes significance between 2 starred groups. † $\dagger$ Denotes significance between 2 daggered groups.

30-day survival, and there was $98 \%$ survival from discharge to 1 year. The 1 death was an 85 -year-old woman who died of complications after a stroke 4 months postdischarge.
In subanalysis of the last 3 years of the study period $(\mathrm{N}=46 / 55)$, improved survival was noted with only 1 death $(2 \%)$ during the modern era. The 1 death was a 76 -year-old woman who presented after multiple syncopal episodes and hypoxia leading to a preoperative stroke and withdrawal of care postoperatively.

Overall, RV dysfunction significantly decreased postoperatively with all patients but 1 with no or mild RV dysfunction (Table 4, Figure 3) $(P<.001)$. In the 1 patient whose $\mathrm{RV}$ dysfunction improved from severe preoperatively to only moderate postoperatively, significant chronic thromboembolic disease was identified at the time of the operation but was not able to be thoroughly addressed.

Nine percent of patients (5/55) developed acute kidney injury postoperatively. However, no patients required hemodialysis by discharge or had a new cerebrovascular accident. One patient had a deep sternal wound infection, and 1 patient developed sepsis postoperatively.

\section{DISCUSSION}

In this study, we sought to analyze in-hospital survival and RV dysfunction after surgical pulmonary embolectomy for acute submassive and massive PE. We found excellent

TABLE 4. Operative and postoperative outcomes

\begin{tabular}{|c|c|c|c|c|c|}
\hline & Overall $(n=55)$ & Submassive $(n=28)$ & $\begin{array}{l}\text { Massive without } \\
\text { arrest }(n=18)\end{array}$ & Massive with arrest $(n=9)$ & $P$ value \\
\hline CPB time (min) & $66(53-96)$ & $64(56-89)$ & $64(49-90)$ & $98(58-141)$ & NS \\
\hline Operative time (min) & $183(154-235)$ & $173(149-223)$ & 177 (154-197) & $238(183-264)$ & NS \\
\hline Ventilator time $(\mathrm{h})$ & $23(9-59)$ & $15(5-25)^{*}, \dagger$ & $42(24-166)^{*}$ & $181(23-298) \dagger$ & .004 \\
\hline Prolonged intubation & $26(47 \%)$ & $7(25 \%)^{*}, \dagger$ & $12(67 \%)^{*}$ & $7(88 \%) \dagger$ & $<.001$ \\
\hline Tracheostomy & $4(7 \%)$ & $0(0 \%)$ & $2(11 \%)$ & $2(22 \%)$ & .037 \\
\hline ICU LOS (d) & $4(3-7)$ & $3(2-4)^{*}, \dagger$ & $5(3-8) *$ & $12(9-29) \dagger$ & .002 \\
\hline Hospital LOS (d) & $8(5-11)$ & $7(5-10)^{*}$ & $7(5-9) \dagger$ & $13(10-43)^{*}, \dagger$ & .026 \\
\hline $\begin{array}{l}\text { RV dysfunction (predischarge) } \\
\text { None } \\
\text { Mild } \\
\text { Moderate } \\
\text { Severe }\end{array}$ & $\begin{array}{c}32(59 \%) \\
9(16 \%) \\
1(2 \%) \\
0(0 \%)\end{array}$ & $\begin{array}{c}15(53 \%) \\
5(18 \%) \\
1(4 \%) \\
0(0 \%)\end{array}$ & $\begin{array}{c}12(67 \%) \\
1(6 \%) \\
0(0 \%) \\
0(0 \%)\end{array}$ & $\begin{array}{l}5(56 \%) \\
3(33 \%) \\
0(0 \%) \\
0(0 \%)\end{array}$ & NS \\
\hline Acute kidney injury & $5(9 \%)$ & $2(7 \%)$ & $2(1 \%)$ & $1(11 \%)$ & NS \\
\hline New dialysis & $0(0 \%)$ & $0(0 \%)$ & $0(0 \%)$ & $0(0 \%)$ & - \\
\hline Pneumonia & $5(9 \%)$ & $1(4 \%)$ & $2(11 \%)$ & $2(22 \%)$ & NS \\
\hline Stroke & $0(0 \%)$ & $0(0 \%)$ & $0(0 \%)$ & $0(0 \%)$ & NS \\
\hline DSWI & $1(2 \%)$ & $0(0 \%)$ & $0(0 \%)$ & $1(11 \%)$ & NS \\
\hline Sepsis & $1(2 \%)$ & $1(4 \%)$ & $0(0 \%)$ & $0(0 \%)$ & NS \\
\hline In-hospital and 30-d survival & $51(93 \%)$ & $28(100 \%)$ & $16(88 \%)$ & $7(78 \%)$ & .033 \\
\hline 1-y survival & $91 \%$ & $100 \% *$ & $88 \%$ & $67 \% *$ & .009 \\
\hline
\end{tabular}

Prolonged intubation: $>24$ hours postoperatively. $C P B$, Cardiopulmonary bypass; $N S$, not significant; $I C U$, intensive care unit; $L O S$, length of stay; $R V$, right ventricular; $D S W I$, deep sternal wound infection. *Denotes significance between 2 starred groups. †Denotes significance between 2 daggered groups. 

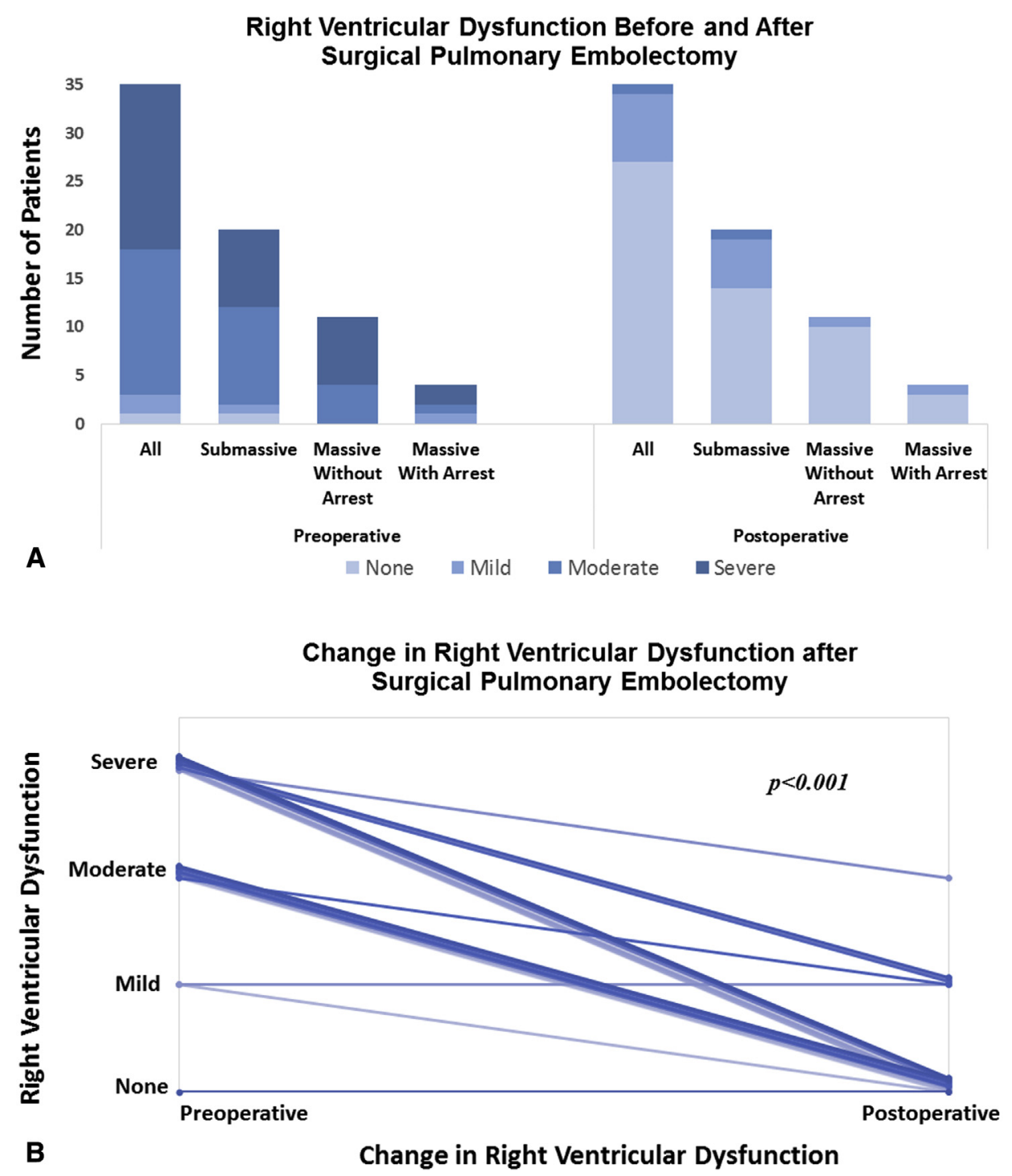

FIGURE 2. A, Stacked graph representing RV function preoperatively and postoperatively. B, Change in RV dysfunction after surgical pulmonary embolectomy.

survival, near normalization of RV function, and minimal morbidity in this series. Our in-hospital survival was $93 \%$ with $100 \%$ survival in patients with submassive PE. Furthermore, there was only 1 death at midterm follow-up in this series (Video 1).

Currently, the AHA and American College of Chest Physicians recommend systemic thrombolysis as first-line therapy in patients with a massive $\mathrm{PE}$ and consideration of thrombolysis in patients with a submassive PE. ${ }^{7,25}$ These recommendations are based, in part, on large, nonrandomized registry data, including International Cooperative Pulmonary Embolism Registry, the Computerized Registry of Patients with Venous Thromboembolism (RIETE), and Multicenter Emergency
Medicine Pulmonary Embolism in the Real World Registry, which have shown a trend toward lower mortality. However, when analyzing the studies individually, none of these reports show a statistically significant difference in mortality after thrombolysis for even massive PE. ${ }^{4,6,26}$ In fact, both the RIETE and the Multicenter Emergency Medicine Pulmonary Embolism in the Real World Registry suggest an increase in overall mortality in a propensitymatched analysis of patients with submassive PE. ${ }^{6,26}$ Furthermore, several randomized control trials, comparing anticoagulation alone with anticoagulation and fibrinolytics for patients with a submassive PE, showed no statistically significant difference in mortality. ${ }^{8,27-29}$ This was maintained even in 2 of the 3 major meta-analyses. ${ }^{30-32}$ 


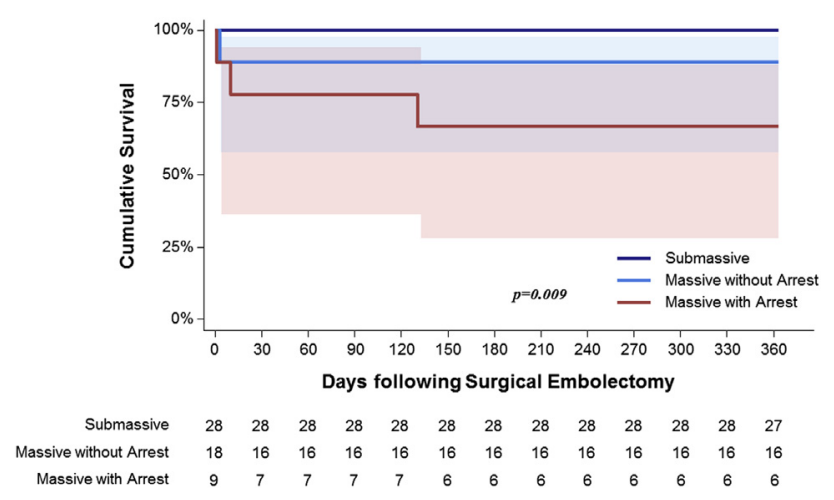

FIGURE 3. Kaplan-Meier survival curves for submassive (dark blue), massive without arrest (light blue), and massive with arrest (red) in patients undergoing surgical pulmonary embolectomy.

Moreover, fibrinolysis was associated with a rate of major hemorrhage up to $11.4 \% .^{8,27-29}$

Although this study is retrospective in nature and has no comparison group, the median estimated mortality for our submassive PE cases was $15.5 \%$, based on the Bova score. $^{22,33}$ This is consistent with a $10 \%$ to $24.5 \%$ median estimated mortality range based on the PESI scores for the submassive PE cases. ${ }^{23,34}$ Although these prediction models have inherent limitations and should not serve as a direct comparator to our results, the estimated $15.5 \%$ mortality provides a reference point to gauge the safety of this surgical therapy. The $0 \%$ mortality in the submassive PE cohort supports the notion that surgical pulmonary embolectomy is a safe treatment for patients with a submassive PE.

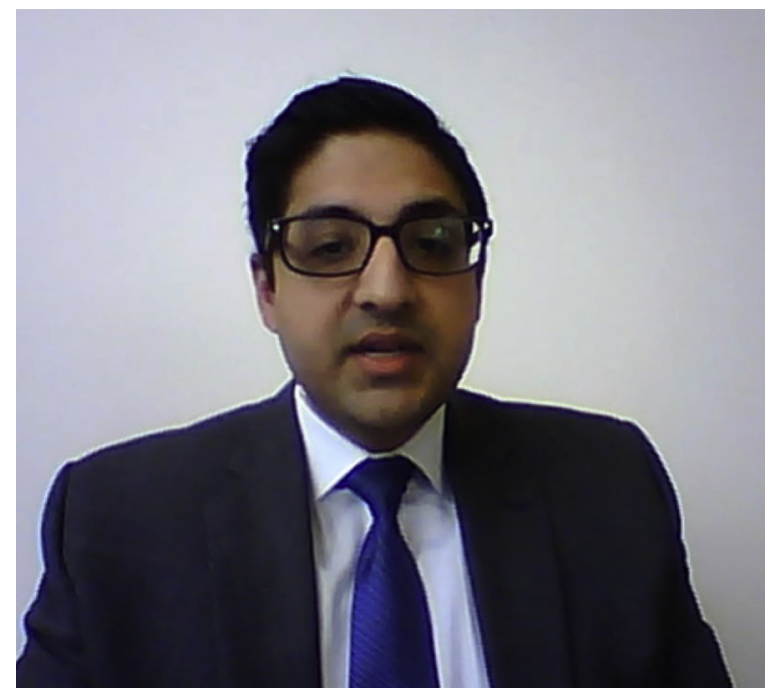

VIDEO 1. The study's lead author discusses the article and importance of this research. Video available at: http://www.jtcvsonline.org/article/S00225223(17)32768-X/fulltext.
In the massive PE cohorts, the median estimated mortality ranged from $10 \%$ to $24.5 \%$, based on the PESI score, and $55.1 \%$, based on the International Cooperative Pulmonary Embolism Registry. ${ }^{4}$ In patients who require cardiopulmonary resuscitation, the Moderate Pulmonary Embolism Treated with Thrombolysis trial demonstrated a mortality rate of $64.8 \%{ }^{35}$ In the current study, the $12 \%$ mortality rate in massive PE cases without arrest and $22 \%$ mortality rate in massive PE cases with arrest suggests the safety of surgical therapy for patients with a massive PE.

Over the past decade, catheter-directed thrombolysis with and without ultrasound therapy has gained popularity and has been proposed as a minimally invasive alternative to surgical pulmonary embolectomy. ${ }^{36,37}$ However, the data thus far have been limited to 1 randomized trial along with small prospective and retrospective series. The UltrasoundAssisted Thrombolysis of Pulmonary Embolism randomized trial compared ultrasound-assisted catheter-directed thrombolysis with heparin alone in patients with a submassive $\mathrm{PE}^{38}$ Although there were no mortalities in the catheterbased arm of the study, the mean RV/left ventricular (LV) ratio was still greater than 0.9 by 90 days. This study was followed by the SEATTLE II trial, which analyzed 149 patients who underwent ultrasound-assisted catheter-directed thrombolysis for a massive or submassive PE. ${ }^{39}$ The primary end point in this study was RV/LV ratio, which again remained considerably elevated at 48 hours postprocedure. In addition, patients received a follow-up computed tomography scan to quantify the amount of remaining pulmonary artery occlusion, which demonstrated that $70 \%$ of the original occlusion, based on the Miller Index, still remained present. Moreover, previous studies have shown other catheter-based therapies to be associated with clot fragmentation and late pulmonary hypertension. ${ }^{40}$ In contrast, in this study, only 1 patient $(1.8 \%)$ remained with an RV/LV ratio greater than 0.9. In that patient, who also remained with moderate RV dysfunction, significant chronic thromboembolic disease was identified intraoperatively. However, this was early in our center's experience. We have subsequently made significant efforts to identify these patients preoperatively and address this problem. These include historical factors, such as history of venous thromboembolism or progressive development of dyspnea or exercise intolerance over months to years, along with careful review of imaging, looking specifically for an enlarged pulmonary artery to aorta ratio and webbing or moth-eaten distal pulmonary vasculature. The data in the present study support the notion that surgical pulmonary embolectomy is an effective treatment for submassive and massive PE.

Multiple reports over the past decade, including surgical pulmonary embolectomy series by Neely and colleagues ${ }^{17}$ and Keeling and colleagues, ${ }^{18}$ have demonstrated outstanding outcomes for patients with a submassive and massive PE. ${ }^{20,41-44}$ Similar to our series, Neely and colleagues ${ }^{17}$ report an overall mortality rate of $7 \%$, and 
Keeling and colleagues ${ }^{18}$ report only 1 death in their series of 44 patients. We believe that the present study adds a modern cohort to the published reports and further suggests that surgical pulmonary embolectomy can be performed with low morbidity and mortality. These series over the past decade challenge the previously published data from the Nationwide Inpatient Sample, which showed an overall mortality rate of $27.2 \%$ for surgical embolectomy. ${ }^{14}$

This series is limited by the retrospective nature of the study. There is no control group to compare outcomes; therefore, mortality and morbidity can be assessed only in relation to historical data. However, our analysis does provide an estimated mortality rate for the study population based on 2 internally and externally validated prediction models. Although there was a younger median patient age in our study compared with the Bova model (53 vs 72 years), age was not found to be a predictor of outcome in the model or in our experience.

The data in this study are the first large surgical series of pulmonary embolectomy to detail patient presentation, both by vital signs and by RV dysfunction. Furthermore, this study adds a modern cohort of patients suggesting that pulmonary embolectomy is safe and effective. Still, over the 5 years of the study, we rapidly improved our surgical timing, perioperative management, and operative procedure in these patients. Given that the majority of deaths in this study were secondary to devastating preoperative neurologic injuries, we no longer advocate to take these patients directly to the operating room for surgical pulmonary embolectomy and believe that other tools should be used in this cohort. Over the last 3 years of the study period, there has only been only 1 death in 46 patients who received surgical pulmonary embolectomy, secondary to a preoperative neurologic event. We attribute the increased success over time to a greater familiarity with the diverse presentation of these patients, better perioperative management and triage, and an improved, standardized surgical technique.

\section{CONCLUSIONS}

Based on the minimal morbidity and mortality, and RV recovery seen in this study, further investigation in the use of surgical pulmonary embolectomy as the definitive treatment for acute submassive and massive PE is warranted.

\section{Conflict of Interest Statement}

Authors have nothing to disclose with regard to commercial support.

\section{References}

1. Office of the Surgeon General (US); National Heart, Lung, and Blood Institute. Section I: deep vein thrombosis and pulmonary embolism as major public health problems. In: The Surgeon General's Call to Action to Prevent Deep Vein Thrombosis and Pulmonary Embolism. Rockville, MD: Office of the Surgeon General (US); 2008:9-18.
2. White RH, Romano PS, Zhou H, Rodrigo J, Bargar W. Incidence and time course of thromboembolic outcomes following total hip or knee arthroplasty. Arch Intern Med. 1998;158:1525-31.

3. Heit JA. The epidemiology of venous thromboembolism in the community. Arterioscler Thromb Vasc Biol. 2008;28:370-2.

4. Kucher N, Rossi E, De Rosa M, Goldhaber SZ. Massive pulmonary embolism. Circulation. 2006;113:577-82.

5. Sharifi M, Bay C, Skrocki L, Rahimi F, Mehdipour M. Moderate pulmonary embolism treated with thrombolysis (from the "MOPETT" Trial). Am J Cardiol. 2013;111:273-7.

6. Riera-Mestre A, Jimenez D, Muriel A, Lobo JL, Moores L, Yusen RD, et al. Thrombolytic therapy and outcome of patients with an acute symptomatic pulmonary embolism. J Thromb Haemost. 2012;10:751-9.

7. Jaff MR, McMurtry MS, Archer SL, Cushman M, Goldenberg N, Goldhaber SZ, et al. Management of massive and submassive pulmonary embolism, iliofemoral deep vein thrombosis, and chronic thromboembolic pulmonary hypertension. Circulation. 2011;123:1788-830.

8. Meyer G, Vicaut E, Danays T, Agnelli G, Becattini C, Beyer-Westendorf J, et al. Fibrinolysis for patients with intermediate-risk pulmonary embolism. $N$ Engl J Med. 2014;370:1402-11

9. Kanter DS, Mikkola KM, Patel SR, Parker JA. Thrombolytic therapy for pulmonary embolism: frequency of intracranial hemorrhage and associated risk factors. Chest. 1997;111:1241-5.

10. Levine MN. Thrombolytic therapy for venous thromboembolism: complications and contraindications. Clin Chest Med. 1995;16:321-8.

11. Berkowitz SD, Granger CB, Pieper KS, Lee KL, Gore JM, Simoons M, et al. Global Utilization of Streptokinase and Tissue plasminogen activator for Occluded coronary arteries (GUSTO-I) Investigators. Incidence and predictors of bleeding after contemporary thrombolytic therapy for myocardial infarction. Circulation. 1997;95:2508-16.

12. The National Institute of Neurological Disorders and Stroke rt-PA Stroke Study Group. Tissue plasminogen activator for acute ischemic stroke. N Engl J Med. 1995;333:1581-7.

13. Kalra R, Bajaj N, Ather S, et al. Mortality outcomes for surgical pulmonary embolectomy for high-risk pulmonary embolism: a comprehensive meta-analysis. $J$ Am Coll Cardiol. 2016;67:2249.

14. Kalra R, Bajaj N, Ather S, Guichard J, Lancaster W, Raman F, et al. Nationwide outcomes of surgical embolectomy for acute pulmonary embolism. J Thorac Cardiovasc Surg. 2013;145:373-7.

15. Meyer G, Tamisier D, Sors H, Stern M, Vouhé M. Pulmonary embolectomy: a 20year experience at one center. Ann Thorac Surg. 1991;51:232-6.

16. Samoukovic G, Malas T, deVarennes B. The role of pulmonary embolectomy in the treatment of acute pulmonary embolism: a literature review from 1968 to 2008. Interact Cardiovasc Thorac Surg. 2010;11:265-70.

17. Neely RC, Byrne JG, Gosey I, Cohn LH, Javed Q, Rawn JD, et al. Surgical embolectomy for acute massive and submassive pulmonary embolism in a series of 115 patients. Ann Thorac Surg. 2015;100:1245-52.

18. Keeling WB, Leshnower BG, Lasajanak Y, Binongo J, Guyton RA, Halkos ME, et al. Midterm benefits of surgical pulmonary embolectomy for acute pulmonary embolus on right ventricular function. J Thorac Cardiovasc Surg. 2016;152: $872-8$.

19. Aklog L, Williams CS, Byrne JG, Goldhaber SZ. Acute pulmonary embolectomy: a contemporary approach. Circulation. 2002;105:1416-9.

20. Leacche M, Unic D, Goldhaber SZ, Rawn JD, Aranki SF, Couper GS, et al. Modern surgical treatment of massive pulmonary embolism: results in 47 consecutive patients after rapid diagnosis and aggressive surgical approach. J Thorac Cardiovasc Surg. 2005;12:1018-23.

21. He C, Von Segesser LK, Kappetein PA, Mestres CA, Smith JA, Choong CK. Acute pulmonary embolectomy. Eur J Cardiothorac Surg. 2013;43:1087-95.

22. Bova C, Sanchez O, Prandoni P, Lankeit M, Konstantinides S, Vanni S, et al. Identification of intermediate-risk patients with acute symptomatic pulmonary embolism. Eur Respir J. 2014;44:694-703.

23. Aujesky D, Obrosky DS, Stone RA, Auble TE, Perrier A, Cornuz J, et al. Derivation and validation of a prognostic model for pulmonary embolism. Am J Respir Crit Care Med. 2005;172:1041-6.

24. Kostrubiec M, Pruszczyk P, Bochowicz A, Pacho R, Szulc M, Kaczynska A, et al Biomarker-based risk assessment model in acute pulmonary embolism. Eur Heart J. 2005;26:2166-72.

25. Kearon C, Akl EA, Ornelas J, Blaivas A, Jimenez D, Bounameaux H, et al. Antithrombotic therapy for VTE disease: CHEST guideline and expert panel report. Chest. 2016;149:315-52. 
26. Lin BW, Schreiber DH, Liu G, Briese B, Hiestand B, Slattery D, et al. Therapy and outcomes in massive pulmonary embolism from the Emergency Medicine Pulmonary Embolism in the Real World Registry. Am J Emerg Med. 2012;30: 1774-81.

27. Konstantinides S, Geibel A, Heusel G, Heinrich F, Kasper W, et al. Heparin plus alteplase compared with heparin alone in patients with submassive pulmonary embolism. N Engl J Med. 2002;347:1143-50.

28. Becattini C, Agnelli G, Salvi A, Grifoni S, Pancaldi LG, Enea I, et al. Bolus tenecteplase for right ventricle dysfunction in hemodynamically stable patients with pulmonary embolism. Thromb Res. 2010;125:e82-6.

29. Kline JA, Nordenholz KE, Courtney DM, Kabrhel C, Jones AE, Rondina MT, et al. Treatment of submassive pulmonary embolism with tenecteplase or placebo: cardiopulmonary outcomes at 3 months: multicenter double-blind, placebo-controlled randomized trial. J Thromb Haemost. 2014;12:459-68.

30. Xu Q, Huang K, Zhai Z, Yang Y, Wang J, Wang C. Initial thrombolysis treatment compared with anticoagulation for acute intermediate-risk pulmonary embolism: a meta-analysis. J Thorac Dis. 2015;7:810-21.

31. Marti C, John G, Konstantinides S, Combescure C, Sanchez O, Lankeit M, et al. Systemic thrombolytic therapy for acute pulmonary embolism: a systematic review and meta-analysis. Eur Heart J. 2015;36:605-14.

32. Chen H, Ren C, Chen H. Thrombolysis versus anticoagulation for the initial treatment of moderate pulmonary embolism: a meta-analysis of randomized controlled trials. Respir Care. 2014;59:1880-7.

33. Fernandez C, Bova C, Sanchez O, Prandoni P, Lankeit M, Konstantinides S, et al. Validation of a model for identification of patients at intermediate to high risk for complications associated with acute symptomatic pulmonary embolism. Chest. 2015;148:211-8.

34. Weeda ER, Kohn CG, Fermann GJ, Peacock WF, Tanner C, McGrath D, et al. External validation of prognostic rules for early post-pulmonary embolism mortality: assessment of a claims-based and three clinical-based approaches. Thromb J. 2016;14:7.

35. Kasper W, Konstantinides S, Geibel A, Olschewski M, Heinrich F, Grosser KD, et al. Management strategies and determinants of outcome in acute major pulmonary embolism: results of a multicenter registry. J Am Coll Cardiol. 1997;30: 1165-71.

36. Bagla S, Smirniotopoulos JB, van Breda A, Sheridan MJ, Sterling KM. Ultrasound-accelerated catheter-directed thrombolysis for acute submassive pulmonary embolism. J Vasc Interv Radiol. 2015;26:1001-6.

37. Engelberger RP, Moschovitis A, Fahrni J, Willenberg T, Baumann F, Diehm N, et al. Fixed low-dose ultrasound-assisted catheter-directed thrombolysis for intermediate and high-risk pulmonary embolism. Eur Heart J. 2015;36:597-604.

38. Kucher N, Boekstegers P, Müller OJ, Kupatt C, Beyer-Westendorf J, Heitzer T, et al. Randomized, controlled trial of ultrasound-assisted catheter-directed thrombolysis for acute intermediate-risk pulmonary embolism. Circulation. 2014;129:479-86.

39. Piazza G, Hohlfelder B, Jaff MR, Ouriel K, Engelhardt TC, Sterling KM, et al. A prospective, single-arm, multicenter trial of ultrasound-facilitated, catheterdirected, low-dose fibrinolysis for acute massive and submassive pulmonary embolism: the SEATTLE II Study. JACC Cardiovasc Interv. 2015;8:1382-92.

40. Goldhaber SZ. Integration of catheter thromboembolectomy into our armamentarium to treat acute pulmonary embolism. Chest. 1998;114: 1237-8.

41. Aymard T, Kadner A, Widmer A, Basciani R, Tevaearai H, Weber A, et al. Massive pulmonary embolism: surgical embolectomy versus thrombolytic therapy-should surgical indications be revisited? Eur J Cardiothorac Surg. 2013;43: 90-4.

42. Carvalho EM, Macedo Fl, Panos AL, Ricci M, Salerno TA. Pulmonary embolectomy: recommendation for early surgical intervention. J Card Surg. 2010;25:261-6.

43. Takahashi H, Kenji O, Masamichi M, Kano H, Kitagawa A, Okita Y. Aggressive surgical treatment of acute pulmonary embolism with circulatory collapse. Ann Thorac Surg. 2012;94:785-91.

44. Azari A, Bigdelu L, Moravvej Z. Surgical embolectomy in the management of massive and sub-massive pulmonary embolism: the results of 30 consecutive ill patients. ARYA Atheroscler. 2015;11:208-13.

Key Words: pulmonary embolism, pulmonary embolectomy, surgical pulmonary embolectomy, submassive and massive pulmonary embolism
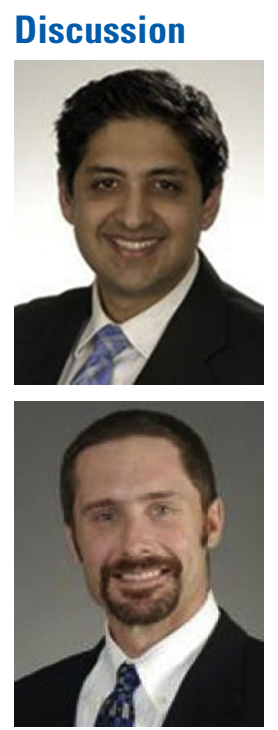

Discussant. Dr Michael Mulligan

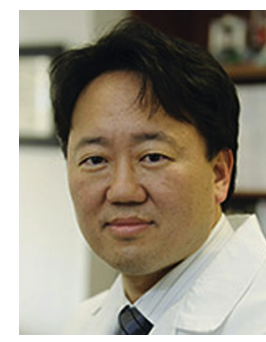

Discussant 2. Dr Murray Kwon

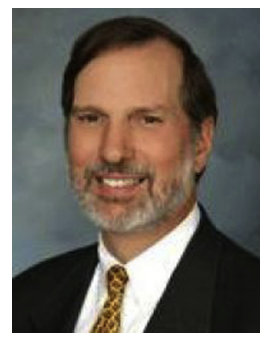

Discussant 3. Dr Joe Bavaria

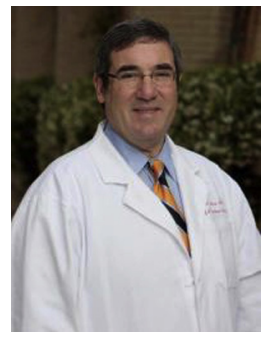

Discussant 4. Dr Richard Shemin

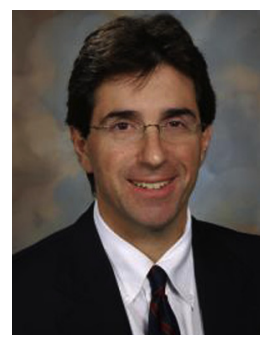

Moderator. Dr Craig H. Selzman

Presenter. Dr Chetan Pasrija.

Moderator. Our final paper for this session, also a Sampson Paper, is coming out of the University of Maryland, 
Chetin Pasrija, "Outcomes After Surgical Pulmonary Embolectomy for Acute Submassive and Massive Pulmonary Embolism: A Single-Center Experience."

Presenter. Thank you for the opportunity to present. It's truly a pleasure to speak in front of the Western community here. We have no disclosures.

According to the Surgeon General, PE is attributable to between 100,000 and 180,000 deaths per year. That remains the most preventable cause of death among hospitalized patients according to the Centers for Disease Control and Prevention. You can get a sense of how morbid this condition can be just taking a look at the clappard in this picture here. PE is a wide spectrum of disease. It ranges from a simple PE, a patient with normal blood pressure with no RV dysfunction or hypotension. The mortality rate for this condition is $0 \%$ to $2 \%$. This ranges up to a submassive PE, a patient with RV dysfunction but no hypotension. The mortality rate for this is $2 \%$ to $15 \%$, up to a massive PE with mortality rates of $15 \%$ and $65 \%$ in patients who require cardiopulmonary resuscitation. The available therapies to treat this condition include systemic anticoagulation to increasingly more invasive therapies, including systemic thrombolysis, catheter-based therapy, and surgical pulmonary embolectomy. Although surgical therapy is the most invasive, we postulate it may be the most effective.

We retrospectively reviewed all consecutive patients undergoing a surgical pulmonary embolectomy between 2011 and 2015 at a single center. We stratify patients by submassive PE, massive PE without arrest, and massive PE with arrest. Our primary outcomes were in-hospital and 1-year survival. Our secondary outcomes were RV dysfunction postoperatively, postoperative stroke, renal failure as defined by the STS, new hemodialysis at discharge, deep sternal wound infection, and sepsis. Our operative techniques involve a media sternotomy followed by initiation of cardiopulmonary bypass with mild hypothermia, used by cable venous cannulation and central aortic cannulation. We then mobilize the aorta and superior vena cava, and we make separate incisions into the right and left main pulmonary artery. We remove thrombus up to the level of the subsegment and visualize every segment for freedom of clot. We use 15- to 30-second circulatory arrest periods as necessary for visualization. We do not routinely cross them for this procedure.

Indications for operation at our institution include a patient with a massive $\mathrm{PE}$ who is an operative candidate or a patient with a submassive PE with a 30-day predicted mortality of greater than $5 \%$ as defined by a number of prediction miles, including the Bova score, PESI score, or positive cardiac biomarkers. Our cohort included 55 patients; 28 had a submassive PE, 18 had a massive PE without arrest, and 9 had a massive PE with arrest. Patients had a median age of 53 years. The majority of patients were male and white. The majority of these patients had a deep vein thrombosis based on lower-extremity venous duplex. Patients were often obese, and $40 \%$ had undergone recent surgery within 1 month, the most common of which was orthopedic surgery. Preoperatively, the median RV dysfunction in the submassive group was moderate. In the massive with arrest group, it was moderate to severe and severe RV dysfunction. We further demonstrated RV strain by troponin release and a positive $\mathrm{N}$-terminal prohormone of brain natriuretic peptide.

Our perioperative outcomes demonstrated a median operative time of approximately 3 hours with a median cardiopulmonary bypass time of approximately 1 hour. Patients were on the ventilator for approximately 1 day, a bit shorter in the submassive group, longer in the massive without arrest group, and longest in the massive with arrest group. The intensive care unit length of stay was shortest in the submassive group, a bit longer in the massive without arrest group, and the longest in the massive with arrest group. The median hospital length of stay was 1 week. In the massive with arrest group, it was approximately 2 weeks. Postoperatively, the median RV function had normalized in every subset. Five patients developed renal failure as defined by the STS, but no patients required dialysis by discharge. There were no postoperative strokes. One patient had a deep sternal wound infection requiring pectoralis advancement flaps, and 1 patient developed sepsis requiring antibiotic therapy.

The overall in-hospital survival was $93 \%$ with $100 \%$ survival in the submassive PE cohort, $88 \%$ survival in the massive without arrest cohort, and $78 \%$ survival in the massive with arrest cohort. There was 1 death between discharges in 1 year. This was a patient in the massive with arrest cohort who died 4 months postoperatively of complications of a cerebrovascular accident unrelated to the initial procedure. This patient did have postoperative echocardiography at 3 months postoperatively, which demonstrated normal RV function. In the past 12 months, we have not had any mortalities in any of these cohorts. Taking a look at the RV function more closely with a stack graph, the increasing shades of green represents increasing severity of RV dysfunction. You can see that preoperatively, the majority of patients had moderate or severe RV dysfunction. Postoperatively, at predismissal echocardiograms, the majority of patients had no or mild RV dysfunction in all cohorts. In redemonstrating our survival with this KaplanMeier curve, we see $100 \%$ survival in our submassive PE cohort and the black line up top up to 1 year: $88 \%$ survival in our massive PE without arrest cohort at 30 days and up to 1 year and 78\% 30-day or in-hospital survival for the massive PE with arrest cohort, with 1 death occurring postoperatively.

Again, to serve as a reference point for what the median mortality should be, in a patient treated with medical therapy, this X represents a $50.5 \%$ median predicted mortality 
based on Bova score if a patient was treated with medical therapy. This is up to a $25 \%$ mortality in the massive PE without arrest cohort and a $65 \%$ mortality in the massive PE with arrest cohort. This study demonstrates excellent in-hospital and midterm outcomes with surgical pulmonary embolectomy. Postoperatively, patients' RV function normalized, and we had $91 \%$ overall survival at 1 year with $100 \%$ survival in the submassive PE cohort. Although these results are hypotheses generating, we think we need a prospective trial to establish the role of surgical pulmonary embolectomy and the wide spectrum of PE.

Moderator. The paper is open for discussion to begin with Dr Mulligan.

Dr Mulligan. As you have alluded to, controversy persists about the optimal management in these patients, and we need to remain self-critical and thoughtful about the topic. I have 2 comments and 4 questions. First, in your article, you were critical of AHA and ACCP treatment guidelines based on data from the large registries and several randomized controlled trials. I would caution you about being too critical because in your current experience, you have no control group who received alternative interventions. The treatment can be safe, but that does not mean it is necessary. Second, greater than $99 \%$ of pulmonary emboli resolve without chronic residual traumas when patients are given anticoagulation from home. This is why trials comparing heparin alone with heparin and thrombolytics for submassive PE failed to demonstrate additional benefit. As such, although you demonstrate acute resolution of RV strain and dilation after embolectomy, similar outcomes are likely with anticoagulation on longer-term follow-up. My first question relates to the patient you describe, who was found to have chronic thromboembolic pulmonary hypertension that was not recognized until the patient was in the operating room. How did this get missed and why was it "unable to be thoroughly addressed intraoperatively" as you stated in your article?

Presenter. Just to reiterate what you said in terms of your second comment and the development of chronic thromboembolic pulmonary hypertension (CTEPH) in these patients and long-standing pulmonary hypertension, you're absolutely correct that the majority of patients in general don't develop CTEPH with just anticoagulation. However, the map of trial in 2012 showed us that in patients with a submassive PE, $15 \%$ to $20 \%$ of those patients develop pulmonary hypertension at a median of 28 months postoperatively. In terms of your question, why were we not able to remove the chronic disease and why was it not recognized in that 1 patient. This was early in our experience. Since then, we have taken significant efforts to identify this preoperatively. Often, when a patient presents with an acute $\mathrm{PE}$, he is rushed to the operating room without specific analysis of the computed tomography scan. Often, it's a very subtle historical finding when you ask the patient, and he says I felt fine until just the other day when I became acutely short of breath, but when you delve further, he says oh yeah, well, I slowly have been feeling slowly short of breath over the past year. The computed tomography findings are subtle and in large pulmonary artery mosaicism on the computed tomography scan. Since then, we've taken specific efforts to address this with all the surgeons such that those questions and findings are addressed. We are in the process of reviewing acute and chronic conditions.

Dr Mulligan. My second question relates to the seemingly subtle differences between your massive and massive with arrest populations. You reported only a 1-point difference in systolic blood pressure between the 2 groups of massive PE and only a 10\% difference between groups in terms of hospital mortality. Most series demonstrate poor survival among patients requiring ongoing cardiopulmonary resuscitation. Is your arrest group requiring continuous cardiopulmonary resuscitation or did they require it only episodically at some point preoperatively?

Presenter. In terms of the first part of that question, the differences in terms of the vital signs between the 2 patients, I think part of the limitation of that is that it's unable to be captured in a retrospective nature when you're looking through charts and for the blood pressures, heart rates, and so forth in those patients. In terms of the second part of your question, whether these patients were requiring continuous cardiopulmonary resuscitation, there was a subset of those 9 patients. I believe 4 of those 9 patients were requiring continuous cardiopulmonary resuscitation when they were placed on venoatrial extracorporeal membrane oxygenation (ECMO) as a bridge to operation.

Dr Mulligan. Earlier, you presented data in 55 patients treated over approximately 5 years at a major university medical center with an associated trauma hospital. There had to be more patients than those admitted with submassive and massive PE. Who did you turn down and what criteria did you use to do so?

Presenter. The 55-patient cohort, we believe, represents quite a few patients. The previous large cohorts that were represented by the Brigham group and Emory group were published over approximately 15 years. Ours was over 5 years, and 55 patients is, we believe, the largest per year representation of that; however, you are correct. There is a subset of patients who we had to turn down. Often, we did operate on patients of advanced age or patients with very advanced age and significant comorbidities were referred to potentially other therapies, including catheterdirected therapy.

Dr Mulligan. In 2007, the University of Michigan group published their experience with extracorporeal life support for these patients and demonstrated that after 3 to 5 days on heparin alone, only $15 \%$ required surgical embolectomy to 
wean off support. These are older data. With more rapid next-generation extracorporeal life support deployment and the ability for extracorporeal life support to provide a safe platform for more involved catheter-based therapies, results are bound to improve. Why not put the patients who are arresting or about to do so on extracorporeal life support and treat from there?

Presenter. That's exactly what we have started doing. Over the past 2 years, any patient with a massive PE who presents with end-organ dysfunction is placed on venoarterial ECMO. We have a series of approximately 20 patients, and what we've found is approximately one third of them with heparin therapy alone resolve, whereas two thirds of them require some type of further intervention.

Dr Kwan. I believe you alluded to your median pump times being approximately 60 minutes and the use of circulatory arrest. That seems fairly short, so what percentage of your patients received circulatory arrest and what was the decision tree in getting therapy and deciding which patients who would receive that?

Presenter. In our current cohort over the past 2 years, the majority of our patients do require short circulatory arrest periods. The reason we do that is just for better visualization. Essentially, we believe that with those short circulatory arrest periods, we can avoid crossclamping and the ischemia, especially with an already sick RV, while having good visualization with that short period.

Moderator. Dr Bavaria.

Dr Bavaria. When I was a resident, Bill Norwood used to always say to me there's a big difference between anatomy and physiology. They're not the same. When you talk about your submassive PE, what is the definition? Is it a physiologic definition or is it an anatomic definition or some combination because there's a really big difference between those 2 concepts and regarding indications for surgery.

Presenter. We agree completely. Submassive PE is defined physiologically by patients who have RV dysfunction, and you're absolutely right. Often, patients can have $\mathrm{PE}$ with central thrombus, but the RV is completely normal. We don't operate on those patients if they don't have a predicted mortality of greater than $5 \%$. Patients can have peripheral PE but every segment can be included, and they can have severe RV dysfunction and be very sick.
Moderator. Dr Shemin?

Dr Shemin. I'd like to just give a few comments on the group that had massive PE and cardiac arrest. I was surprised to see no strokes. Most of those patients during cardiopulmonary resuscitation have very little oxygen tension, and it takes times to organize an ECMO team to the bedside and then transfer to the operating room. What are you doing that's special to the situation with physical obstruction, low cardiac output, cardiac arrest, and low oxygen tension to have no strokes?

Presenter. As I was saying earlier, we're aggressive about placing these patients on venoarterial ECMO. This actually functions now as a bridge to triage, so we place the patients on a venoarterial ECMO, and it gives us time to figure out whether these patients have neurologic death. If they do, then care is withdrawn, and if we find that they have good neurologic status then once their end-organ function is optimized, they're taken to the operating room for an embolectomy or if the clot has resolved, they're just decannulated from ECMO.

Dr Shemin. Do you actually have a PE team or a protocol such that you are able to mobilize your group and get patients out of the medical intensive care unit or wherever they might be? We don't do 1 of these a month. You're doing basically 1 of these a month right now, it sounds like. You've obviously educated your institution, so can you describe your PE team or your protocol?

Presenter. We've done a couple things to try and increase how patients can get to our facility and services a bit quicker. We have a critical care attending and a cardiac surgeon always on call for PE.

Dr Shemin. You have a PE pager just like an acute STelevation myocardial infarction pager when there's a PE in the institution or does it go out to a group or a team?

Presenter. No, we don't have a specific PE pager, but we have educated teams around our hospital, and we've actually gone out to referral centers all across the state to function as a hub and spoke center for PE, and whether it's a simple or massive PE, we have told other centers that they're welcome and we ask them to call us, and we're willing to take care of that full spectrum of PE.

Dr Shemin. Well done. We'll reconvene at 11. 


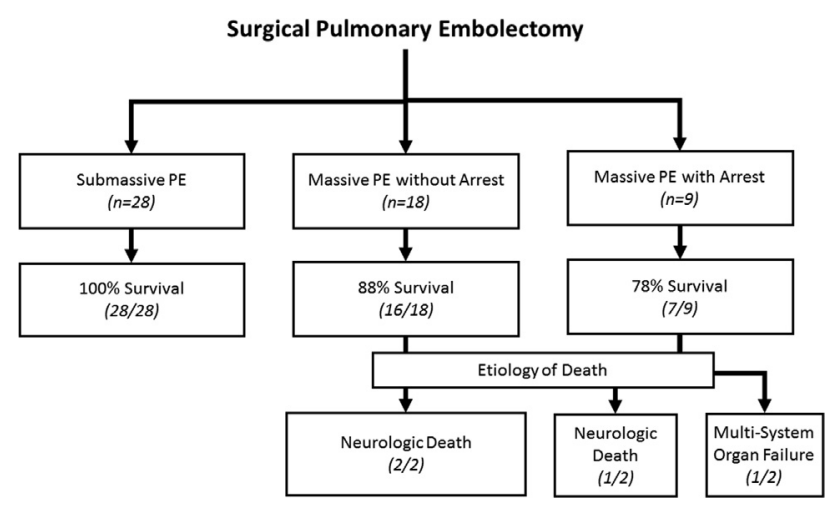

FIGURE E1. Flowchart describing survival in each cohort and cause of mortalities. PE, Pulmonary embolism.

TABLE E1. Preoperative Pulmonary Embolism Score Index characteristics

\begin{tabular}{|c|c|c|c|c|c|}
\hline & $\begin{array}{c}\text { Overall } \\
(\mathbf{n}=\mathbf{5 5})(\%)\end{array}$ & $\begin{array}{c}\text { Submassive } \\
(n=28)(\%)\end{array}$ & $\begin{array}{c}\text { Massive without arrest } \\
(\mathrm{n}=18)(\%)\end{array}$ & $\begin{array}{c}\text { Massive with arrest } \\
(\mathbf{n}=9)(\%)\end{array}$ & $P$ value \\
\hline Male sex & $33(60)$ & $17(61)$ & $10(56)$ & $6(67)$ & NS \\
\hline History of heart failure & $1(2)$ & $1(4)$ & $0(0)$ & $0(0)$ & NS \\
\hline $\begin{array}{l}\text { History of chronic lung } \\
\text { disease }\end{array}$ & $5(9)$ & $2(7)$ & $2(11)$ & $1(11)$ & NS \\
\hline Saturation $<90 \%$ & $31(56)$ & $13(46)$ & $13(72)$ & $5(56)$ & NS \\
\hline $\mathrm{HR} \geq 110$ beats $/ \mathrm{min}$ & $38(69)$ & $22(79)$ & $11(61)$ & $5(56)$ & NS \\
\hline $\mathrm{RR} \geq 30$ beats/min & $30(55)$ & $16(57)$ & $7(39)$ & $7(78)$ & NS \\
\hline Temperature $<36^{\circ} \mathrm{C}$ & $13(24)$ & $5(18)$ & $5(28)$ & $3(33)$ & NS \\
\hline Malignancy & $8(15)$ & $3(11)$ & $3(17)$ & $2(22)$ & NS \\
\hline $\mathrm{SBP}<100 \mathrm{~mm} \mathrm{Hg}$ & $37(67)$ & $10(36)^{*}, \dagger$ & $18(100)^{*}$ & $9(100) \dagger$ & $<.001$ \\
\hline Altered mental status & $25(46)$ & $8(29)^{*}$ & $12(67)^{*}$ & $5(56)$ & .03 \\
\hline
\end{tabular}

$N S$, Not significant; $H R$, heart rate; $R R$, respiratory rate; $S B P$, systolic blood pressure. *Denotes significance between 2 starred groups. $\dagger$ Denotes significance between 2 daggered groups. 
TABLE E2. Preoperative Bova characteristics for patients with submassive pulmonary embolism

\begin{tabular}{lc}
\hline & Submassive $(\mathbf{n}=\mathbf{2 8})(\mathbf{\%})$ \\
\hline SBP $90-100 \mathrm{~mm} \mathrm{Hg}$ & $10(36)$ \\
Elevated cardiac troponin & $27(96)$ \\
RV dysfunction & $27(96)$ \\
Heart rate $\geq 110$ beats/min & $22(79)$ \\
\hline
\end{tabular}

$S B P$, Systolic blood pressure; $R V$, right ventricular. 